\title{
Escolhas contábeis na demonstração dos fluxos de caixa em companhias listadas no novo mercado da B3
}

\author{
Accounting choices in the statement of cash flows at companies listed in the novo mercado \\ of B3
}

Opciones contables en el estado de flujos de efectivo en las empresas listadas en el novo mercado de B3

\section{Denise Mendes da Silva}

Doutora em Controladoria e Contabilidade pela Faculdade de Economia, Administração e Contabilidade de Ribeirão Preto - Universidade de São Paulo FEA-RP/USP

Professora Adjunta da Faculdade de Ciências Contábeis da Universidade Federal de Uberlândia (FACIC-UFU)

Endereço: Av. João Naves de Avila 2121 Bloco 1F sala 215, Santa Mônica

CEP: 38400902 - Uberlândia, MG - Brasil

E-mail: denysemendes03@gmail.com

Telefone: (34) 3239-4176

\section{Vinícius Aversari Martins}

Doutor em Controladoria e Contabilidade pela Faculdade de Economia, Administração e Contabilidade da Universidade de São Paulo - FEA/USP

Pós-Doutorando na KU Leuven - Faculty of Business and Economics and LICOS Centre for Institutions and Economic Performance, KU Leuven Bélgica

Endereço: Avenida Bandeirantes, 3900 Bloco C, sala 13, Monte Alegre

CEP: 14040900 - Ribeirão Preto, SP - Brasil

E-mail: vinicius@usp.br

Telefone: (16) 3602-3000

\section{Fabiano Guasti Lima}

Doutor em Controladoria e Contabilidade pela Faculdade de Economia, Administração e Contabilidade da Universidade de São Paulo - FEA/USP.

Professor da Faculdade de Economia, Administração e Contabilidade de Ribeirão Preto Universidade de São Paulo - FEA-RP/USP

Endereço: Avenida dos Bandeirantes, 3900, Monte Alegre

CEP: 14040900 - Ribeirão Preto, SP - Brasil

E-mail: fabianoguastilima@gmail.com

Telefone: (16) 36023922

Artigo recebido em 29/01/2018. Revisado por pares em 11/04/2018. Reformulado em 30/05/2018. Recomendado para publicação em 15/10/2018 por Carlos Eduardo Facin Lavarda (Editor-Chefe). Publicado em 19/12/2018. 


\title{
Resumo
}

Este estudo investigou quais fatores podem estar relacionados às escolhas contábeis na DFC realizadas em 112 companhias abertas não financeiras listadas no Novo Mercado da B3 no período de 2010 a 2015. A principal contribuição deste estudo é fornecer um panorama sobre a forma como as empresas consideradas com alto nível de governança corporativa no Brasil estão evidenciando seus fluxos de caixa no que tange à comparabilidade e, também, ao gerenciamento da DFC, fazendo escolhas que impliquem em um aumento do fluxo de caixa operacional. Este estudo oferece evidências de que a maioria das empresas apresenta a DFC pelo método indireto e segue as recomendações de políticas contábeis contidas no CPC 03 para classificar juros e dividendos pagos e recebidos. Além disso, o tamanho da empresa e as oportunidades de crescimento parecem ter relação com as escolhas de classificação de juros pagos e dividendos recebidos, respectivamente. Os resultados no contexto brasileiro diferem de achados anteriores em outros mercados, provavelmente por implicações do ambiente institucional em que as empresas se inserem.

Palavras-chave: Escolhas contábeis; Demonstração dos fluxos de caixa; Fluxo de caixa operacional

\begin{abstract}
This study investigated which factors may be related to the SCF accounting choices made in 112 non-financial companies listed on the B3 Novo Mercado in the period from 2010 to 2015. The main contribution of this study is to provide an overview of how companies considered high level of corporate governance in Brazil are evidencing their cash flows with respect to the comparability and also the management of the SCF, making choices that imply an increase in the operational cash flow. This study provides evidence that most companies present the SCF by the indirect method and follow the accounting policy recommendations contained in CPC 03 to classify interest and dividends paid and received. In addition, the size of the company and the growth opportunities appear to be related to the ratings choices of interest paid and dividends received, respectively. The results in the Brazilian context differ from previous findings in other markets, probably because of the institutional environment in which companies are inserted.
\end{abstract}

Keywords: Accounting choices; Statement of cash flows; Operating cash flow

\section{Resumen}

Este estudio investigó qué factores pueden estar relacionados con las elecciones contables en la EFE realizadas en 112 compañias abiertas no financieras listadas en el Nuevo Mercado de B3 en el periodo de 2010 a 2015. La principal contribución de este estudio es proporcionar un panorama sobre la forma en que las empresas consideradas como el alto nivel de gobierno corporativo en Brasil están evidenciando sus flujos de caja en lo que se refiere a la comparabilidad y, también, al manejo de la EFE, haciendo elecciones que impliquen un aumento del flujo de caja operacional. Este estudio ofrece evidencias de que la mayoría de las empresas presentan la EFE por el método indirecto y sigue las recomendaciones de políticas contables contenidas en el CPC 03 para clasificar intereses y dividendos pagados y recibidos. Además, el tamaño de la empresa y las oportunidades de crecimiento parecen tener relación con las opciones de clasificación de intereses pagados y dividendos recibidos, respectivamente. Los resultados en el contexto brasileño difieren de hallazgos anteriores en otros mercados, probablemente por implicaciones del ambiente institucional en que las empresas se insertan. Palavras-clave: Opciones contables; Estado de flujos de efectivo; Flujo de caja operativo 


\section{Introdução}

A adoção do padrão contábil internacional no Brasil, por meio da emissão dos Pronunciamentos Técnicos pelo Comitê de Pronunciamentos Contábeis (CPC), convergentes ao International Financial Reporting Standards (IFRS), ampliou as possibilidades de escolhas contábeis e propiciou um amplo cenário para pesquisas relativas a esse tema, pelo fato de o IFRS requerer mais julgamento dos gestores na implementação das normas.

Ao longo dos anos, pesquisadores buscaram explicações para as escolhas contábeis realizadas nas empresas e identificaram que estas podem estar relacionadas a aspectos econômicos e contratuais, de acordo com as Teorias da Agência e Contratual, e com as hipóteses dos planos de incentivo, do endividamento e dos custos políticos, integrantes da Teoria Positiva da Contabilidade, conforme apontaram os estudos de Holthausen e Leftwich (1983), Holthausen (1990), Watts (1992) e Fields, Lys e Vincent (2001). Esses estudos sugerem que as escolhas contábeis são realizadas no intuito de maximizar a riqueza da empresa (perspectiva de contratação eficiente), para transferir riqueza entre os diversos agentes (perspectiva oportunista) ou para fornecer informações sobre fluxos de caixa futuros da empresa, sem afetá-los diretamente (perspectiva informacional). A partir dessa vertente literária, outros estudos empíricos foram desenvolvidos a fim de encontrar explicações para as escolhas contábeis, incluindo incentivos econômicos e contratuais, refletidos em características das empresas, especialmente, rentabilidade, endividamento e tamanho, entre os quais, Cole, Branson \& Breesch, 2013; Gordon et al. 2013; Baik et al. 2016, Gordon et al. 2017.

As escolhas contábeis podem se referir à mensuração de ativos (estoques, propriedades para investimento etc.), ao reconhecimento de eventos no Balanço Patrimonial e/ou na Demonstração do Resultado (depreciação, subvenções governamentais, ativos financeiros etc.), à apresentação de informações (método de apresentação do fluxo de caixa das atividades operacionais na Demonstração dos Fluxos de Caixa (DFC), forma de apresentação dos componentes de outros resultados abrangentes etc.) e à classificação de itens nas demonstrações contábeis, como, por exemplo, dos juros e dividendos pagos e recebidos na DFC.

No que tange à apresentação da DFC, pelos itens 18 a 20A do Pronunciamento Técnico CPC 03 - Demonstração dos Fluxos de Caixa, as empresas podem escolher entre o método direto ou indireto para apresentar o fluxo de caixa das atividades operacionais (CPC, 2010). Essa escolha é válida desde que, ao optar pelo método direto, a entidade forneça, obrigatoriamente, em notas explicativas, a conciliação entre o lucro líquido e o fluxo de caixa líquido das atividades operacionais, assim como é apresentado no método indireto.

$\mathrm{Na}$ norma original do International Accounting Standards Board (IASB), IAS 7 Statement of Cash Flows - emitida em 1992, com última revisão em 2016 (IFRS FOUDATION, 2016), é incentivada a utilização do método direto, assim como na norma do Financial Accounting Standards Board (FASB), FAS 95, de mesmo nome, emitida em 1987 (FASB, 1987), porém esse incentivo não está explícito no CPC 03. Em termos de escolha contábil, a falta de incentivo explícito na norma nacional pode representar uma flexibilidade adicional para os gestores, visto que uma recomendação normativa por um método preferencial de apresentação da DFC pode ter efeitos de um benchmarking.

Em relação à classificação dos fluxos de caixa, a IAS 7 é um pouco mais flexível do que a norma FAS 95 (norte-americana). De acordo com a IAS 7, juros e dividendos pagos podem ser classificados tanto nas atividades operacionais como nas de financiamento; juros e dividendos recebidos podem ser classificados tanto nas atividades operacionais como nas de investimento. Já pela norma norte-americana (FAS 95), juros pagos e juros e dividendos recebidos devem ser classificados nas atividades operacionais.

No Brasil, o CPC 03 mantém a flexibilidade original da IAS 7. No item 33 do CPC 03 é justificado que os juros pagos e recebidos e os dividendos e os juros sobre o capital próprio 
recebidos podem ser classificados como fluxos de caixa operacionais, porque eles entram na determinação do lucro líquido ou prejuízo e ainda, os juros pagos e os juros, os dividendos e os juros sobre o capital próprio recebidos podem ser classificados, respectivamente, como fluxos de caixa de financiamento e fluxos de caixa de investimento, porque são custos de obtenção de recursos financeiros ou retornos sobre investimentos.

Apesar dessas justificativas, o CPC, por meio do item 34A do CPC 03, encoraja fortemente as entidades a classificarem os juros, recebidos ou pagos, e os dividendos e juros sobre o capital próprio recebidos, como fluxos de caixa das atividades operacionais, e os dividendos e juros sobre o capital próprio pagos, como fluxos de caixa das atividades de financiamento, e que alternativa diferente da encorajada deve ser seguida de nota explicativa evidenciando esse fato (CPC, 2010). Não há esse encorajamento na norma original do IASB, portanto, na norma nacional (CPC) há recomendação de classificações preferenciais (benchmarking), o que pode, inclusive, restringir a escolha contábil por parte dos gestores. Importante lembrar que para as instituições financeiras os juros fazem parte das atividades operacionais.

Estudos como os de Bradbury (2011), Bond, Bugeja e Czernkowski (2012) e Clacher; Ricquebourg e Hodgson (2013), na Austrália, demonstraram que a apresentação da DFC pelo método direto permite melhor previsão de fluxos de caixa e desempenho futuros, além de ter uma associação mais forte com o preço das ações (value relevance). Os autores explicam que tais resultados podem estar atrelados ao fato de que o método direto já era utilizado pelas empresas da Austrália antes mesmo da possibilidade de escolha entre os dois métodos de apresentação da DFC. Por sua vez, Hales e Orpurt (2013) e Andrade e Silva (2017) fizeram uma revisão da literatura internacional a respeito da escolha de apresentação da DFC pelo método direto ou indireto e concluíram que há evidências de que a apresentação pelo método direto é mais útil para tomada de decisão e que os benefícios de tal informação provavelmente excedem o custo de obtê-la.

Outros estudos abordaram as escolhas de classificação na DFC, tais como os de Nobes (2011), Lee (2012), Scherer et al. (2012), Cole, Branson e Breesch (2013), Gordon et al. (2013), Baik et al. (2016) e Maciel, Salotti e Imoniana (2017). Nobes (2011), em amostra de empresas europeias, e Scherer et al. (2012), em uma amostra de empresas listadas em quatro diferentes bolsas, se atentaram na identificação das escolhas realizadas, sem, necessariamente, relacionálas a aspectos econômicos e contratuais, ao passo que os demais estudos citados evidenciaram tais aspectos, incluindo características institucionais, como país de origem das empresas, setor e firma de auditoria, como visto em Cole, Branson e Breesch (2013), na Europa, e em Maciel, Salotti e Imoniana (2017), no Brasil. Por sua vez, Lee (2012), Gordon et al. (2013) e Baik et al. (2016), em empresas da base Compustat, da Europa e da Coreia do Sul, respectivamente, demonstraram que fluxos de caixa idênticos em sua natureza podem ser classificados de várias formas pelas empresas, devido à opção permitida pela norma (IAS 7, FAS 95), à situação financeira das empresas, a incentivos do mercado de capitais, à situação de endividamento e lucratividade.

Como pode ser visto, tais estudos não abordaram o relacionamento das escolhas contábeis na DFC com os aspectos econômicos e contratuais, preconizados pelas Teorias da Agência, Contratual e Positiva da Contabilidade no contexto brasileiro, peculiar, notadamente pelo baixo acesso das empresas ao mercado de capitais e pela ausência de um mercado consolidado de dívidas de longo prazo (TORRES FILHO; COSTA, 2012), mesmo os estudos nacionais. Tais peculiaridades podem afetar a estrutura patrimonial das empresas, bem como, o desempenho destas, que podem adotar mecanismos de gerenciamento dos seus fluxos de caixa, por meio de escolhas contábeis, diferentes de outras empresas em outros mercados.

Adicionalmente, outro fator não considerado nos estudos anteriores refere-se ao nível de governança corporativa das empresas. Verriest, Gaeremynck e Thornton (2013) alertam que 
as empresas exibem heterogeneidade na qualidade de conformidade e divulgação de informações contábeis e que algumas nem sequer cumprem os requisitos mínimos de divulgação. Além disso, tais autores afirmam que a adoção do IFRS exige que as empresas divulguem informação financeira adicional e decidam sobre compliance voluntário e opções de divulgação.

Conforme Verriest, Gaeremynck e Thornton (2013), mecanismos de governança mais fortes (como o Novo Mercado, no Brasil, por exemplo) podem estar associados a um melhor compliance e divulgação de maior qualidade relativa à adoção do IFRS. Se isso se aplicar ao contexto brasileiro, a expectativa é que haja um isomorfismo nas escolhas contábeis das empresas pertencentes a um mesmo nível de governança corporativa e, então, quais seriam os fatores relacionados às escolhas contábeis de tais empresas? Essa perspectiva não foi considerada e testada em estudos anteriores, como os de Maciel, Salotti e Imoniana (2017) e Pinto et al. (2018), que abarcaram as companhias listadas no Brasil.

Considerando o exposto, o presente estudo investiga quais fatores podem estar relacionados às escolhas contábeis na DFC realizadas nas companhias abertas não financeiras consideradas como de alto nível de Governança Corporativa no Brasil. Para isso foram analisadas as demonstrações contábeis de 112 empresas não financeiras listadas no Novo Mercado da B3, referentes ao período de 2010 a 2015, último ano com demonstrações contábeis publicamente disponíveis na época de realização da pesquisa (janeiro e fevereiro de 2017).

A partir das análises realizadas, que envolveram o teste de Mann-Whitney e a regressão logística, verificou-se que as escolhas contábeis predominantes na amostra são: método indireto para apresentação da DFC; classificação de juros (pagos e recebidos) e dividendos e juros sobre o capital próprio recebidos no fluxo de caixa operacional; classificação de dividendos e juros sobre capital próprio pagos no fluxo de caixa de financiamento. Isso implica dizer que as companhias listadas no Novo Mercado, considerado como de alto nível de governança corporativa no Brasil, apresentam compliance com as políticas contábeis recomendadas pelo CPC 03. Ademais, identificou-se que o tamanho e as oportunidades de crescimento parecem ter relação com as escolhas de classificação de juros pagos e dividendos recebidos na DFC, respectivamente, considerando a amostra e o período estudados. De modo geral, os resultados encontrados não coincidem com pesquisas anteriores em outros mercados (Gordon et al., 2013; Baik et al., 2016), provavelmente por implicações de outras variáveis aqui não analisadas, tais como aquelas que refletem algum aspecto do ambiente institucional (setor, auditoria, país de origem ou de controle da empresa etc.).

A principal contribuição deste estudo é oferecer evidências sobre a realização de escolhas contábeis no Brasil, por meio da busca de características das empresas que podem determinar as escolhas contábeis na DFC. Em outras palavras, este estudo pode oferecer um panorama sobre a forma como as empresas consideradas com alto nível de governança corporativa no Brasil estão evidenciando seus fluxos de caixa no que tange à comparabilidade e, também, ao gerenciamento da DFC, fazendo escolhas que impliquem em um aumento do fluxo de caixa operacional. As conclusões aqui apresentadas podem ser úteis para o órgão normatizador (CPC), a fim de sinalizar possíveis eliminações de flexibilidade de políticas contábeis, notadamente em se tratando de práticas em que já há uma política preferencial recomendada pelos órgãos (IASB/CPC), bem como, para fomentar o debate em torno do método de apresentação da $\mathrm{DFC}$, tendo em vista a predominância do uso do método indireto e a preferência dos normatizadores (IASB/FASB) pelo método direto.

\section{Revisão da Literatura e Elaboração das Hipóteses}

As escolhas contábeis na DFC podem referir-se ao método de apresentação do fluxo de 
caixa operacional (método direto ou indireto) e à classificação dos juros, dividendos e juros sobre o capital próprio pagos e recebidos no fluxo de caixa operacional, de financiamento ou de investimento (CPC, 2010; IFRS FOUDATION, 2016; FASB, 1987). Cabe ressaltar que este estudo não considera a classificação dos impostos sobre o lucro (imposto de renda e contribuição social) como uma escolha contábil, haja vista o disposto no item 35 do CPC 03, o qual preconiza que os fluxos de caixa dos referidos impostos devem ser divulgados separadamente e devem ser classificados como fluxos de caixa das atividades operacionais, a menos que possam ser identificados especificamente como atividades de financiamento e de investimento (CPC, 2010). Portanto, não se trata de uma escolha contábil, mas sim, de uma determinação da norma.

No tocante ao método de apresentação, Abu-Abbas (2014) relata que, pela literatura, a maioria das empresas usa apenas o método indireto, apesar de alguns estudos indicarem que o método direto é mais útil para a tomada de decisão e para a previsão de fluxos de caixa e desempenho, podendo, inclusive, gerar reflexos nos preços das ações (BRADBURY, 2011; BOND; BUGEJA; CZERNKOWSKI, 2012; CLACHER; RICQUEBOURG; HODGSON, 2013; HALES; ORPURT, 2013). Contudo, Hales e Orpurt (2013) alertam que ainda não há estudos que detalhem como essa informação impacta nos preços das ações. Portanto, nesse aspecto, há um distanciamento entre as conclusões apresentadas nos estudos mencionados e a prática observada no mercado.

Abu-Abas (2014) elenca algumas vantagens de ambos os métodos. Afirma que o método direto é mais consistente com o objetivo de uma DFC, pois melhora a capacidade de previsão dos fluxos de caixa operacionais futuros e fornece informações mais úteis para os credores e investidores. Por outro lado, o método indireto é mais fácil para os preparadores elaborarem e para os usuários analisarem, destaca as diferenças entre o lucro líquido e o caixa líquido das atividades operacionais e tem menor custo de implementação.

Apesar da preferência do IASB pelo método direto para apresentação da DFC, nos estudos da KPMG em coautoria com a Profa. Isabel Von Keitz (KPMG; VON KEITZ, 2006) e de Nobes (2011), Scherer et al. (2012) e Cole, Branson e Breesch (2013) foi constatado o domínio da apresentação da DFC pelo método indireto nas empresas das amostras analisadas. Tais pesquisas abrangeram, notadamente, empresas em países da Europa. Em se tratando do estudo de Scherer et al. (2012), a amostra foi composta por companhias listadas em quarto diferentes bolsas.

O estudo da KPMG e Von Keitz (2006) abrangeu empresas de diversos países em diferentes continentes que adotaram o IFRS. Os autores demonstraram que a classificação de juros pagos e recebidos e de dividendos recebidos no fluxo de caixa operacional e a classificação de dividendos pagos no fluxo de caixa de financiamento foram escolhas de grande parte das empresas pesquisadas. Quanto aos juros pagos, o estudo mostrou a predominância da classificação no fluxo de caixa operacional em todos os países e setores analisados, mais fortemente, ainda, na Suécia e na França, embora tais resultados não possam ser explicados pelo GAAP anterior desses dois países, segundo os pesquisadores.

Nobes (2011) investigou o método de apresentação da DFC e a classificação dos juros pagos no fluxo de caixa operacional ou de financiamento, entre outras escolhas contábeis. Essa pesquisa, feita com empresas de oito países (Austrália, Reino Unido, Alemanha, Espanha, Suécia, Itália, França e Holanda) que adotaram o IFRS, evidenciou a predominância do método indireto para apresentação da DFC, exceto na Austrália, onde era exigido o método direto antes da adoção do IFRS. Também foi predominante a classificação dos juros pagos no fluxo de caixa operacional em todos os países, exceto na Espanha.

Cole, Branson e Breesch (2013) pesquisaram empresas de 7 países europeus listadas em bolsa e pertencentes aos setores de bens industriais e serviços, finanças e tecnologia. Sobre as escolhas de classificação na DFC, os autores encontraram resultados semelhantes ao estudo da 
KPMG e Von Keitz (2006), com exceção dos dividendos recebidos, os quais foram classificados no fluxo de caixa de investimento pela maioria das empresas que pesquisaram. Adicionalmente, tal estudo demonstrou que a classificação de juros pagos pode estar relacionada ao país de origem das empresas, à auditoria e ao tamanho da empresa, ao passo que a classificação de juros recebidos pode estar relacionada ao país, ao setor e à auditoria.

No Brasil, Scherer et al. (2012), analisaram, entre outros aspectos, o tratamento dado aos juros e dividendos pagos e recebidos na DFC em 229 empresas listadas nas bolsas de São Paulo, Frankfurt, Milão e Londres. Esses autores verificaram que a classificação de juros pagos e recebidos no fluxo de caixa operacional e a classificação de dividendos pagos no fluxo de caixa de financiamento foram as escolhas predominantes, enquanto houve equilíbrio na classificação dos dividendos recebidos em tais empresas, similarmente ao que demonstraram KMPG e Von Keitz (2006), Nobes (2011) e Cole, Branson e Breesch (2013).

Ainda no Brasil, Maciel, Salotti e Imoniana (2017) evidenciaram que a maior parte das companhias brasileiras não financeiras listadas na B3 segue as classificações encorajadas pelo item 34A do CPC 03, exceto quanto aos dividendos e juros sobre o capital próprio recebidos. Além disso, os autores apontaram indícios de que alguns setores e algumas empresas de auditoria podem influenciar as escolhas de classificação na DFC. Nessa mesma linha de estudos, encontra-se o trabalho de Pinto et al. (2018), o qual adiciona a discussão sobre comparabilidade de escolhas contábeis, que, segundo os autores, aumentou gradativamente no período estudado, denotando melhora na qualidade da informação contábil. Ressalta-se que nenhum dos estudos realizados no contexto brasileiro aqui mencionados consideraram o nível de governança corporativa em suas análises acerca das escolhas contábeis na DFC. Nesse sentido, o presente estudo difere dos anteriores.

Especificamente com relação às escolhas de classificação na DFC, estudos anteriores indicam que essas podem variar devido à situação financeira das empresas, a incentivos do mercado de capitais, à situação de endividamento e à lucratividade, conforme evidenciaram Lee (2012), Gordon et al. (2013) e Baik et al. (2016), em diferentes mercados. As conclusões desses autores vão ao encontro do que prega as Teorias da Agência, Contratual e Positiva da Contabilidade, relativamente ao fato de que aspectos econômicos e contratuais podem explicar as escolhas contábeis nas empresas, neste caso, inclusive aquelas relativas à DFC.

Lee (2012) alerta que o gerenciamento de resultados é diferente do gerenciamento dos fluxos de caixa, pois enquanto o primeiro manipula os accruals, o segundo não permite esse tipo de manipulação. Mesmo assim, pode haver o gerenciamento dos fluxos de caixa por meio da classificação dos fluxos entre as atividades (operacionais, de investimento e de financiamento) e do timing, como por exemplo, atrasar pagamentos a fornecedores ou antecipar recebimentos de clientes. Lee (2012) pesquisou empresas não financeiras e de setores não regulados nos anos de 1988 a 2008 na base Compustat e identificou quatro características corporativas relacionadas a incentivos para aumentar o fluxo de caixa operacional: i) dificuldades financeiras, ii) rating de crédito de longo prazo próximo ao ponto de corte da categoria de investimento/não investimento, iii) existência de previsões de fluxo de caixa dos analistas, e iv) maiores associações entre retornos das ações e caixa das operações.

Por sua vez, Gordon et al. (2013) acrescentaram outros aspectos ao rol de possíveis explicações para a realização de escolhas contábeis na DFC. Os autores focaram empresas não financeiras de 13 países europeus que adotaram o IFRS a partir de 2005 e indicaram que os três primeiros fatores (situação financeira das empresas, incentivos do mercado de capitais e situação de endividamento) apresentaram relação com a classificação dos fluxos de caixa das empresas da amostra (escolha de classificações que aumentam o fluxo de caixa operacional), porém a lucratividade não apresentou relação com essa escolha. De acordo com os autores, as escolhas podem variar, também, conforme o ambiente de divulgação, considerando: a existência de projeção de fluxos de caixa pelos analistas, práticas do setor e se a empresa está 
listada nos Estados Unidos. Os dois primeiros aspectos (projeção de fluxos de caixa e práticas do setor) não se mostraram significantes para as escolhas de classificação dos fluxos de caixa. Já o fato da empresa estar listada nos Estados Unidos não a impede de fazer escolhas de classificação, mesmo que essas escolhas não sejam permitidas pelo USGAAP, segundo dados da pesquisa.

Gordon et al. (2013) explicam que empresas com dificuldades financeiras são motivadas a relatar maior fluxo de caixa operacional, porque esta é uma importante medida na avaliação de crédito e risco. As atividades operacionais são as principais geradoras de receitas e, quanto maior a capacidade de geração de fluxos de caixa operacionais, maior a capacidade de pagamento. Os autores ainda expõem que as empresas que acessam mais frequentemente os mercados de capitais têm fortes incentivos para inflar os fluxos de caixa operacionais no intuito de aumentar o volume de captação (ou capitalização). Empresas mais endividadas, com maiores custos de renegociação de dívidas também tendem a relatar maiores fluxos de caixa operacionais.

Desse modo, no intuito de avaliar a relação entre o endividamento das empresas e as escolhas contábeis na DFC no contexto brasileiro, peculiar pela sua característica de inexistência de um mercado consolidado de dívidas de longo prazo (TORRES FILHO; COSTA, 2012) e considerando-se o nível de governança corporativa das empresas, tem-se a primeira hipótese deste estudo:

H1 - o nível de endividamento possui relação com as escolhas contábeis na DFC realizadas nas companhias abertas não financeiras listadas no Novo Mercado da B3.

Ainda conforme Gordon et al (2013), empresas lucrativas e/ou com fluxos de caixa operacionais negativos buscam classificações que permitam relatar maior fluxo de caixa operacional (FCO). Reportar maior FCO reforça a avaliação da rentabilidade e empresas com FCO negativo possuem incentivos para classificações que o torne menos negativo ou mesmo positivo, como por exemplo, não classificar juros pagos como operacionais (GORDON et al., 2013). Nessa linha de raciocínio, para testar a relação da rentabilidade e do valor positivo ou negativo do fluxo de caixa operacional com as escolhas contábeis na DFC em empresas listadas no Brasil em alto nível de governança corporativa, apresenta-se a segunda e a terceira hipóteses:

$\mathrm{H} 2$ - o índice de rentabilidade possui relação com as escolhas contábeis na DFC realizadas nas companhias abertas não financeiras listadas no Novo Mercado da B3.

H3 - o valor (positivo ou negativo) do fluxo de caixa operacional possui relação as escolhas contábeis na DFC realizadas nas companhias abertas não financeiras listadas no Novo Mercado da B3.

Por fim, Baik et al. (2016) examinaram os determinantes e consequências econômicas das mudanças de classificação dos juros pagos na DFC de 1.424 empresas não financeiras listadas no mercado de capitais da Coreia do Sul que adotaram o IFRS obrigatoriamente em 2011. Encontraram que empresas com alta alavancagem, grandes empresas e aquelas que são acompanhadas por poucos analistas tendem a mudar os pagamentos de juros dos fluxos operacionais para os fluxos de financiamento, aumentando, assim, o total do fluxo de caixa operacional. Também consideraram que empresas com oportunidades de crescimento, já que exigem altos investimentos, têm incentivos para manter altos níveis de fluxos de caixa operacionais para atrair provedores de capital. Nessa mesma lógica, a fim de analisar a relação entre tais características (tamanho da empresa e oportunidades de crescimento) e as escolhas contábeis na DFC no contexto de empresas listadas no Brasil em elevado nível de governança corporativa, têm-se a quarta e a quinta hipóteses deste trabalho:

H4 - o tamanho da empresa possui relação com as escolhas contábeis na DFC realizadas nas companhias abertas não financeiras listadas no Novo Mercado da B3.

H5 - as oportunidades de crescimento possuem relação com as escolhas contábeis na DFC realizadas nas companhias abertas não financeiras listadas no Novo Mercado da B3. 
Em linha com os trabalhos mencionados, este estudo parte do pressuposto que as escolhas contábeis variam de empresa para empresa e decorrem de incentivos econômicos, procurando explicar a razão pela qual podem ocorrer diferentes escolhas contábeis na DFC. Importante destacar que as escolhas contábeis relativas a fluxos de caixa restringem-se a classificações sem levar em conta operações mais sofisticadas, como securitização, por exemplo, na qual a essência da transação é desmontada e seus fluxos de caixa são 'espalhados' por vários grupos, e que podem, a princípio, ser ajustados pelos analistas e usuários.

\section{Aspectos Metodológicos}

\subsection{Coleta de dados}

A amostra deste estudo foi constituída por 112 empresas não financeiras listadas no Novo Mercado da B3 que divulgaram Demonstrações Contábeis no período de 2010 a 2015, último ano com demonstrações contábeis publicamente disponíveis para todas as empresas da amostra na época de realização da pesquisa (janeiro e fevereiro de 2017). Esse período engloba demonstrações contábeis elaboradas e publicadas no período após a adoção completa dos Pronunciamentos Contábeis convergentes ao IFRS no Brasil.

A escolha dessa amostra justifica-se pelo fato deste estudo buscar analisar as escolhas contábeis na DFC, decorrentes da flexibilidade normativa prevista na adoção do IFRS e considerando-se o nível de governança corporativa no qual as empresas estão listadas, em consonância com o que afirmam Verriest, Gaeremynck e Thornton (2013). Tais autores argumentam que níveis de governança corporativa mais elevados podem estar associados a um melhor compliance e divulgação de informações contábeis de mais qualidade relativa à adoção do IFRS. Caso isso seja atinente ao contexto brasileiro, espera-se que as escolhas contábeis na DFC das empresas em análise sejam homogêneas e busca-se identificar quais aspectos econômicos podem estar relacionados às referidas escolhas.

Apesar do CPC 03 ter sido aplicado desde 2008 pelas empresas da amostra, foi escolhido o período após a adoção completa dos Pronunciamentos Contábeis convergentes ao IFRS, o que pode eliminar efeitos de eventuais ajustes nos diversos componentes patrimoniais e de resultado que são utilizados nas análises deste estudo. Para as análises, foram coletadas as Demonstrações Financeiras Padronizadas (DFP) consolidadas, sempre que disponíveis, referentes aos 6 anos analisados de todas as empresas da amostra. A partir das DFP, foram coletadas, manualmente, todas as escolhas contábeis referentes às classificações de juros, dividendos e juros sobre o capital próprio pagos e recebidos, bem como, a informação se a DFC foi apresentada pelo método direto ou indireto.

\subsection{Procedimentos de análise dos dados}

A análise dos dados deste estudo contemplou duas etapas: análise descritiva e análise multivariada. Os aspectos sobre a DFC considerados na análise descritiva foram:

(i) Método de apresentação direto ou indireto;

(ii) Classificação dos juros, dividendos e juros sobre o capital próprio pagos e recebidos.

Após essa etapa, partiu-se para a seleção de variáveis que poderiam apresentar relação com a escolha de classificação dos juros, dividendos e juros sobre o capital próprio, pagos e recebidos, na DFC, ou seja, com a escolha de adotar classificações que aumentem o fluxo de caixa operacional, conforme a literatura revisada. Tais variáveis correspondem a características das empresas, de acordo com as hipóteses do estudo. Para avaliar a relação entre as escolhas contábeis e as características das empresas foram empregadas técnicas estatísticas de análise multivariada. 
As variáveis foram submetidas ao teste de diferenças de médias de Mann-Whitney, ao nível de significância de 5\%. Esse teste foi aplicado para dois grupos de empresas com distintas escolhas contábeis em relação à classificação de juros e dividendos pagos e recebidos na DFC. $\mathrm{O}$ intuito do teste é verificar se diferentes incentivos econômicos podem ter relação com a realização de escolhas contábeis de classificação na DFC nas empresas da amostra. As hipóteses testadas foram: $H_{0}$ : não há diferenças entre os grupos; e $H_{1}$ : há diferenças entre os grupos.

A análise de regressão logística, para aferir a probabilidade de ocorrência de um evento e identificar características dos elementos pertencentes a cada grupo determinado pela variável categórica, foi procedida na sequência. $\mathrm{O}$ modelo utilizado para análise da relação entre as escolhas contábeis na DFC realizadas nas empresas listadas no Novo Mercado da B3 e os aspectos econômicos de tais empresas está em linha com os estudos que tratam das escolhas contábeis na DFC em outros mercados, tais como os de Lee (2012), Gordon et al. (2013) e Baik et al. (2016) e apresenta-se como segue:

Em que:

$$
C L A S=\beta_{0}+\beta_{1} E N D+\beta_{2} R O E+\beta_{3} F C O+\beta_{4} T A M+\beta_{5} P B+\varepsilon
$$

CLAS = Classificação, sendo 1 para representar a escolha pela classificação no fluxo de caixa das atividades operacionais e 0 , caso a classificação seja em outro fluxo;

END $=$ Endividamento, medido pela relação entre Passivo Oneroso Total (empréstimos, financiamentos, arrendamentos, debêntures, de curto e longo prazo) e Capital Total a Disposição da Empresa, ao final de cada ano;

$\mathrm{ROE}=($ Return on Equity) Retorno sobre o Patrimônio Líquido, medido pelo Lucro Líquido dividido pelo Patrimônio Líquido contábil final de cada ano;

FCO = Fluxo de Caixa Operacional, sendo 1 se a empresa apresentou fluxo de caixa operacional positivo e 0 , caso seja negativo, em cada ano;

$\mathrm{TAM}=$ Tamanho da empresa, medido pelo logaritmo natural do valor contábil do Ativo total em $\mathrm{R} \$$ ao final de cada ano;

$\mathrm{PB}=($ Price-to-book) Relação preço-livro, preço de mercado da ação dividido pelo valor patrimonial da ação ao final de cada ano, proxy para oportunidades de crescimento;

$\varepsilon=$ termo de erro do modelo.

De acordo com a literatura, as relações esperadas entre essas variáveis e as escolhas contábeis que possibilitam o aumento dos fluxos de caixa operacionais são positivas, ou seja, empresas mais endividadas, mais lucrativas, maiores e com mais oportunidades de crescimento tendem a escolher classificações que aumentem os fluxos de caixa operacionais, bem como, aquelas que estão com fluxo de caixa operacional negativo. Assim, a expectativa é que empresas com essas características prefiram classificar o pagamento dos juros, dividendos e juros sobre o capital próprio nas atividades de financiamento e não nas atividades operacionais e, ainda, prefiram classificar o recebimento dos juros, dividendos e juros sobre o capital próprio nas atividades operacionais e não nas atividades de investimento. Essas relações esperadas são resumidas no Quadro 1.

A escolha de classificar juros pagos no fluxo de caixa de financiamento contraria a recomendação de política contábil preferencial de acordo com as normas (CPC/IASB). Caso isso ocorra nas empresas analisadas, pertencentes a um alto nível de governança corporativa, poderá denotar não haver o compliance esperado, conforme argumentos de Verriest, Gaeremynck e Thornton (2013), porém isso não implica, necessariamente, em divulgação de menor qualidade, pois outras características precisam ser consideradas. Em outras palavras, a uniformidade de práticas contábeis não reflete, essencialmente, demonstrações contábeis de maior qualidade, pois o que se deve avaliar não é a comparabilidade das escolhas, mas sim, das 
informações contábeis como um todo, inclusive considerando características institucionais e do ambiente de divulgação. Ainda que se verifique o compliance das escolhas realizadas com as políticas contábeis recomendadas nas normas, os demais aspectos econômicos elencados podem oferecer explicações adicionais para a realização de escolhas contábeis nas empresas brasileiras, na perspectiva de listagem em alto nível de governança corporativa.

Quadro 1 - Relações esperadas entre as variáveis

\begin{tabular}{|c|c|c|c|c|c|c|}
\hline \multirow[t]{2}{*}{ Itens } & \multirow[t]{2}{*}{ Escolha de classificação esperada } & \multicolumn{5}{|c|}{ Relação esperada } \\
\hline & & END & $\mathrm{ROE}$ & $\begin{array}{c}\text { FCO } \\
(-)\end{array}$ & TAM & PB \\
\hline Juros recebidos & Fluxo de caixa operacional & + & + & + & + & + \\
\hline Dividendos e JSCP recebidos & Fluxo de caixa operacional & + & + & + & + & + \\
\hline Juros pagos & Fluxo de caixa de financiamento & + & + & + & + & + \\
\hline Dividendos e JSCP pagos & Fluxo de caixa de financiamento & + & + & + & + & + \\
\hline
\end{tabular}

Notas: JSCP: Juros sobre o Capital Próprio; END: endividamento; ROE: rentabilidade; TAM: tamanho; FCO (-): Fluxo de Caixa Operacional negativo; PB: price-to-book, proxy para oportunidades de crescimento.

É importante ressaltar que os resultados obtidos neste estudo estão limitados às variáveis analisadas. Outras variáveis não consideradas podem influenciar os resultados, o que, contudo, não diminui as contribuições da pesquisa, especialmente pelo seu caráter de originalidade no cenário brasileiro.

\section{Apresentação e Análise dos Resultados}

\subsection{Características das empresas}

Uma visão das características das empresas da amostra no período de 2010 a 2015, pode ser obtida na Tabela 1. De acordo com as informações apuradas na Tabela 1, o endividamento das empresas foi crescente ao longo do período, ao passo que a rentabilidade foi decrescente, assim como as oportunidades de crescimento. Em 2015, em média, pouco mais de um terço do capital total à disposição das empresas correspondeu a capitais onerosos. Por sua vez, a rentabilidade das empresas do Novo Mercado, que foi, em média, de 20,4\% em 2010, caiu para $-15,24 \%$ em 2015 . Durante a pesquisa foi possível observar que a queda na rentabilidade média da amostra foi ocasionada, notadamente, pelos altos prejuízos obtidos por algumas empresas, tais como, Renar Maçãs, Log-in e Lopes Brasil, em 2015, e Lupatech e Viver, em 2014. Não foram investigados os motivos específicos para a geração de prejuízos nessas empresas, pois não é esse o objetivo do estudo, porém, é fato que o Brasil passa por uma grave crise econômica, ainda mais severa nos últimos anos $(2014,2015)$, o que cria uma conjuntura ampla de dificuldades, que pode ter afetado a situação econômico-financeira das empresas.

Devido a essa situação, é natural que as oportunidades de crescimento das empresas se restrinjam, o que pode ser observado por meio da relação entre o preço de mercado da ação e seu valor contábil (price-to-book), que também foi decrescente no período. No entanto, em termos de volume (em reais), o ativo (TAM) e o fluxo de caixa operacional (FCO) das empresas aumentaram no decorrer do período analisado. Isso pode ser um indicativo de que o mercado não está capturando a informação de crescimento das empresas no que diz respeito ao ativo e ao fluxo de caixa operacional, ou seja, esses montantes não refletiram no preço das ações. Pode ser que haja potencial de crescimento, mas dado o risco, o mercado não está apostando que o potencial possa se realizar. 
Tabela 1 - Características das empresas

\begin{tabular}{|c|c|c|c|c|c|c|}
\hline Ano & Variáveis & $\mathrm{N}$ & Mínimo & Máximo & Média & Desvio padrão \\
\hline \multirow{5}{*}{2010} & END & 112 & 0,00 & 65,84 & 26,77 & 16,04 \\
\hline & ROE & 112 & $-59,69$ & 772,76 & 20,37 & 74,49 \\
\hline & $\mathrm{FCO}$ & 112 & $-2.199 .821,00$ & $3.231 .568,00$ & $230.907,75$ & $732.983,97$ \\
\hline & TAM & 112 & 93,00 & $44.529 .225,00$ & $4.972 .668,03$ & $7.056 .273,30$ \\
\hline & $\mathrm{PB}$ & 112 & 0,00 & 31,96 & 3,31 & 4,86 \\
\hline \multirow{5}{*}{2011} & END & 112 & 0,00 & 73,39 & 29,29 & 17,20 \\
\hline & ROE & 112 & $-85,94$ & 553,14 & 15,21 & 58,39 \\
\hline & $\mathrm{FCO}$ & 112 & $-819.428,00$ & $4.129 .443,00$ & $316.513,31$ & $704.734,75$ \\
\hline & TAM & 112 & 136,00 & $47.410 .884,00$ & $5.846 .896,02$ & 7.666.789,39 \\
\hline & $\mathrm{PB}$ & 112 &,- 49 & 22,04 & 2,35 & 3,17 \\
\hline \multirow{5}{*}{2012} & END & 112 & 0,00 & 64,25 & 31,64 & 17,56 \\
\hline & ROE & 112 & $-82,43$ & 295,31 & 11,84 & 38,82 \\
\hline & $\mathrm{FCO}$ & 112 & $-1.322 .580,00$ & $4.965 .169,00$ & $399.526,71$ & $789.776,35$ \\
\hline & TAM & 112 & $78.604,00$ & 49.756.193,00 & $6.664 .831,27$ & $8.233 .599,84$ \\
\hline & $\mathrm{PB}$ & 112 &,- 11 & 38,27 & 2,31 & 4,19 \\
\hline \multirow{5}{*}{2013} & END & 112 & 0,00 & 176,74 & 33,12 & 22,01 \\
\hline & ROE & 112 & $-256,34$ & 179,06 & 4,58 & 46,07 \\
\hline & $\mathrm{FCO}$ & 112 & $-2.570 .977,00$ & $5.269 .502,00$ & $411.521,92$ & $882.675,93$ \\
\hline & TAM & 112 & $92.161,00$ & $68.670 .221,00$ & $7.054 .284,45$ & $9.323 .352,38$ \\
\hline & $\mathrm{PB}$ & 112 &,- 04 & 30,73 & 2,05 & 3,47 \\
\hline \multirow{5}{*}{2014} & END & 112 & 0,00 & 97,43 & 32,49 & 18,86 \\
\hline & ROE & 111 & $-661,73$ & 268,47 & $-0,82$ & 83,23 \\
\hline & $\mathrm{FCO}$ & 112 & $-3.815 .679,00$ & $8.987 .035,00$ & $532.102,33$ & $1.285 .418,63$ \\
\hline & TAM & 112 & $70.155,00$ & $82.043 .682,00$ & $7.585 .952,36$ & $10.571 .611,25$ \\
\hline & PB & 112 &,- 05 & 25,90 & 1,93 & 3,14 \\
\hline \multirow{5}{*}{2015} & END & 112 & 0,00 & 112,17 & 34,04 & 20,96 \\
\hline & ROE & 111 & $-1.504,21$ & 209,00 & $-15,24$ & 159,12 \\
\hline & $\mathrm{FCO}$ & 111 & $-487.659,00$ & $21.206 .366,00$ & $762.427,68$ & $2.179 .529,72$ \\
\hline & TAM & 111 & $24.218,00$ & $121.752 .954,00$ & $8.696 .795,50$ & $14.229 .677,54$ \\
\hline & PB & 112 & $-5,07$ & 21,90 & 1,79 & 3,03 \\
\hline \multirow{5}{*}{$\begin{array}{c}\text { Total } \\
\text { período }\end{array}$} & END & 672 & 0,00 & 176,74 & 31,23 & 18,98 \\
\hline & ROE & 670 & $-1504,21$ & 772,76 & 6,03 & 86,76 \\
\hline & FCO & 671 & $-3.815 .679,00$ & $21.206 .366,00$ & $441.689,33$ & $1.219 .121,86$ \\
\hline & ATIVO & 671 & 93,00 & $121.752 .954,00$ & $6.800 .749,77$ & $9.838 .771,08$ \\
\hline & PB & 672 & $-5,07$ & 38,27 & 2,29 & 3,72 \\
\hline
\end{tabular}

Notas: END: endividamento (\%); ROE: rentabilidade (\%); TAM: tamanho (R\$ mil); FCO: Fluxo de Caixa Operacional (R\$ mil); PB: price-to-book (\%); N: número de observações.

De outro modo, analisou-se o fluxo de caixa operacional categorizado como positivo ou negativo e os resultados encontrados nas empresas no período de 2010 a 2015 são demonstrados na Tabela 2.

Tabela 2 - Fluxo de Caixa Operacional das empresas no período

\begin{tabular}{lcc|cc|cc|cc|cc|cc}
\hline \multirow{2}{*}{ FCO } & \multicolumn{10}{c}{ Quantidade de empresas } \\
\cline { 2 - 28 } & 2010 & $\%$ & 2011 & $\%$ & 2012 & $\%$ & 2013 & $\%$ & 2014 & $\%$ & 2015 & $\%$ \\
\hline Negativo & 33 & 29,5 & 28 & 25,0 & 25 & 22,3 & 21 & 18,8 & 15 & 13,4 & 17 & 15,2 \\
Positivo & 79 & 70,5 & 84 & 75,0 & 87 & 77,7 & 91 & 81,2 & 97 & 86,6 & 94 & 83,9 \\
Total & 112 & 100 & 112 & 100 & 112 & 100 & 112 & 100 & 112 & 100 & 111 & 99,1 \\
\hline
\end{tabular}

Nota: FCO: Fluxo de Caixa Operacional 
Por meio da Tabela 2 verifica-se que a capacidade de gerar fluxos de caixa operacionais positivos aumentou ao longo do período (quase 20\%, se comparar o ano de 2015 ao ano de 2010). Importante lembrar que, conforme explicitado no item 13 do CPC 03, o montante dos fluxos de caixa advindos das atividades operacionais é um indicador chave da extensão pela qual as operações da entidade geram fluxos de caixa suficientes para amortizar empréstimos, manter a capacidade operacional da entidade, pagar dividendos e juros sobre o capital próprio e fazer novos investimentos sem recorrer a fontes externas de financiamento.

Nessa linha de raciocínio, pode-se depreender indícios de gerenciamento de fluxo de caixa, por meio de escolhas contábeis de classificação, tendo em vista que a rentabilidade média das empresas no período foi decrescente e a capacidade de geração de lucros, no longo prazo, reflete a capacidade de geração de caixa. Em outras palavras, se a rentabilidade caiu e o fluxo de caixa operacional aumentou, pode ser que algumas escolhas contábeis de classificação tenham favorecido esse aumento.

Outro fato que pode explicar a inversão de sentidos do fluxo de caixa e rentabilidade é que esta última pode ser afetada por fatores financeiros (despesas financeiras, no geral) que não são capturados pela rentabilidade do capital próprio. Neste estudo, escolheu-se o ROE como proxy para rentabilidade justamente por este motivo, ou seja, uma variável que incorpore o efeito da alavancagem financeira. Para estudos futuros, pode-se empregar uma variável de retorno sobre ativos ou investimentos operacionais, que poderá mostrar o desempenho dos investimentos, independente dos efeitos da estrutura de capital. Outra possível explicação é que o fluxo de caixa operacional não considera os investimentos de longo prazo, mas somente aqueles efetuados no capital de giro. Se o conceito de fluxo de caixa livre da empresa for adotado, pode-se ter resultados diferentes.

Importante ressaltar que essas análises são adicionais, comparativamente a estudos relativos à temática realizados anteriormente. Por exemplo, Gordon et al. (2013) pesquisaram as variáveis endividamento, rentabilidade e fluxo de caixa operacional em 798 empresas de 13 países europeus, porém, não apresentaram nenhuma análise nesse sentido, assim como Baik et al. (2016) que estudaram, além das variáveis já citadas, o tamanho e as oportunidades de crescimento em empresas da Coreia do Sul nos anos de 2011 e 2012. No Brasil, Pinto et al. (2018) avaliaram, no que tange às escolhas contábeis na DFC, as mesmas cinco variáveis em 354 companhias listadas na B3, no período de 2010 a 2015, entretanto, fizeram uma análise descritiva das variáveis por grupo de empresas conforme suas escolhas contábeis e não uma análise longitudinal como a aqui apresentada. Isso impede o cotejamento entre os resultados ora apresentados e os achados de estudos anteriores relacionados.

\subsection{Escolhas contábeis na apresentação da Demonstração dos Fluxos de Caixa}

No que diz respeito ao método de apresentação da DFC, todas as empresas da amostra, exceto uma, escolheram o método indireto, corroborando o estudo da KPMG e Von Keitz (2006) e os estudos de Nobes 2011, Scherer et al. (2012), Cole, Branson e Breesch (2013) e Abu-Abbas, 2014. Apenas a empresa Somos Educação S.A. apresentou a DFC pelo método direto em todo o período analisado.

Em linha com Andrade e Silva (2017), essa escolha predominante pode ser explicada pelo fato de que as empresas que apresentarem o fluxo de caixa das atividades operacionais pelo método direto devem, obrigatoriamente, apresentar a conciliação do lucro líquido, exigida pelo item 20A do CPC 03. Optando pelo método indireto, essa exigência é atendida na própria DFC, o que diminui custos de elaboração e divulgação das informações.

Outras razões também podem ter motivado o emprego do método indireto nas empresas, conforme apontam Andrade e Silva (2017). Por exemplo: a apresentação da DFC pelo método indireto permite aos usuários da informação contábil entender as políticas de 
recebimentos, pagamentos e estocagem. Pelo método indireto é possível compreender a diferença entre regime de caixa e regime de competência e, assim, compreender porque as empresas possuem lucro, mas não possuem caixa e vice-versa.

\subsection{Escolhas contábeis de classificação na Demonstração dos Fluxos de Caixa}

Em se tratando das escolhas de classificação do pagamento e recebimento de juros, dividendos e juros sobre o capital próprio na DFC, foram encontrados os resultados discriminados na Tabela 3.

Tabela 3 - Escolhas contábeis de classificação na DFC

\begin{tabular}{|c|c|c|c|c|c|c|c|c|c|}
\hline Ano & Classificação & \multicolumn{8}{|c|}{ Quantidade de empresas } \\
\hline & \multirow{6}{*}{$\begin{array}{l}\mathrm{N} \\
\text { Operacional } \\
\text { Financiamento } \\
\text { Investimento } \\
\text { Sem informação }\end{array}$} & JP & $\%$ & JR & $\%$ & $\mathrm{DP}$ & $\%$ & DR & $\%$ \\
\hline \multirow{5}{*}{2010} & & 112 & 100,0 & 112 & 100,0 & 112 & 100,0 & 112 & 100,0 \\
\hline & & 80 & 71,4 & 106 & 94,6 & 2 & 1,8 & 89 & 79,4 \\
\hline & & 29 & 25,9 & 1 & 0,9 & 90 & 80,3 & 2 & 1,8 \\
\hline & & & & 2 & 1,8 & & & 18 & 16,1 \\
\hline & & 3 & 2,7 & 3 & 2,7 & 20 & 17,9 & 3 & 2,7 \\
\hline \multirow{5}{*}{2011} & \multirow{5}{*}{$\begin{array}{l}\mathrm{N} \\
\text { Operacional } \\
\text { Financiamento } \\
\text { Investimento } \\
\text { Sem informação }\end{array}$} & 112 & 100,0 & 112 & 100,0 & 112 & 100,0 & 112 & 100,0 \\
\hline & & 79 & 70,5 & 106 & 94,6 & 2 & 1,8 & 89 & 79,4 \\
\hline & & 30 & 26,8 & 1 & 0,9 & 90 & 80,3 & 2 & 1,8 \\
\hline & & & & 2 & 1,8 & & & 18 & 16,1 \\
\hline & & 3 & 2,7 & 3 & 2,7 & 20 & 17,9 & 3 & 2,7 \\
\hline \multirow{5}{*}{2012} & \multirow{5}{*}{$\begin{array}{l}\mathrm{N} \\
\text { Operacional } \\
\text { Financiamento } \\
\text { Investimento } \\
\text { Sem informação }\end{array}$} & 112 & 100,0 & 112 & 100,0 & 112 & 100,0 & 112 & 100,0 \\
\hline & & 79 & 70,5 & 106 & 94,6 & 3 & 2,7 & 81 & 72,3 \\
\hline & & 32 & 28,6 & 2 & 1,8 & 95 & 84,8 & 3 & 2,7 \\
\hline & & & & 3 & 2,7 & & & 27 & 24,1 \\
\hline & & 1 & 0,9 & 1 & 0,9 & 14 & 12,5 & 1 & 0,9 \\
\hline \multirow{5}{*}{2013} & \multirow{5}{*}{$\begin{array}{l}\mathrm{N} \\
\text { Operacional } \\
\text { Financiamento } \\
\text { Investimento } \\
\text { Sem informação }\end{array}$} & 112 & 100,0 & 112 & 100,0 & 112 & 100,0 & 112 & 100,0 \\
\hline & & 79 & 70,5 & 106 & 94,6 & 3 & 2,7 & 82 & 73,2 \\
\hline & & 32 & 28,6 & 2 & 1,8 & 94 & 83,9 & 2 & 1,8 \\
\hline & & & & 3 & 2,7 & 1 & 0,9 & 27 & 24,1 \\
\hline & & 1 & 0,9 & 1 & 0,9 & 14 & 12,5 & 1 & 0,9 \\
\hline \multirow{5}{*}{2014} & \multirow{5}{*}{$\begin{array}{l}\mathrm{N} \\
\text { Operacional } \\
\text { Financiamento } \\
\text { Investimento } \\
\text { Sem informação }\end{array}$} & 112 & 100,0 & 112 & 100,0 & 112 & 100,0 & 112 & 100,0 \\
\hline & & 78 & 69,6 & 106 & 94,6 & 1 & 0,9 & 74 & 66,0 \\
\hline & & 33 & 29,5 & 1 & 0,9 & 98 & 87,5 & 3 & 2,7 \\
\hline & & & & 3 & 2,7 & 1 & 0,9 & 34 & 30,4 \\
\hline & & 1 & 0,9 & 2 & 1,8 & 12 & 10,7 & 1 & 0,9 \\
\hline \multirow{5}{*}{2015} & \multirow{5}{*}{$\begin{array}{l}\mathrm{N} \\
\text { Operacional } \\
\text { Financiamento } \\
\text { Investimento } \\
\text { Sem informação }\end{array}$} & 112 & 100,0 & 112 & 100,0 & 112 & 100,0 & 112 & 100,0 \\
\hline & & 77 & 78,7 & 105 & 93,7 & 1 & 0,9 & 73 & 65,1 \\
\hline & & 33 & 29,5 & 2 & 1,8 & 97 & 86,6 & 3 & 2,7 \\
\hline & & & & 3 & 2,7 & 1 & 0,9 & 34 & 30,4 \\
\hline & & 2 & 1,8 & 2 & 1,8 & 13 & 11,6 & 2 & 1,8 \\
\hline \multirow{5}{*}{$\begin{array}{c}\text { Total } \\
\text { Período }\end{array}$} & $\mathrm{N}$ & 672 & 100,0 & 672 & 100,0 & 672 & 100,0 & 672 & 100,0 \\
\hline & Operacional & 472 & 70,2 & 635 & 94,5 & 12 & 1,8 & 488 & 72,7 \\
\hline & Financiamento & 189 & 28,1 & 9 & 1,3 & 564 & 83,9 & 15 & 2,2 \\
\hline & Investimento & & & 16 & 2,4 & 3 & 0,4 & 158 & 23,5 \\
\hline & Sem informação & 11 & 1,6 & 12 & 1,8 & 93 & 13,9 & 11 & 1,6 \\
\hline
\end{tabular}

Notas: JP: juros pagos; JR: juros recebidos; DP: dividendos e juros sobre o capital próprio pagos; DR: dividendos e juros sobre capital próprio recebidos; N: número de observações. Os valores destacados em cinza referem-se a escolhas contábeis divergentes das possibilidades de classificação de fluxos de caixa conforme as normas vigentes (CPC 03 e IAS 7). 
Conforme observa-se na Tabela 3, não foi possível identificar as escolhas contábeis de classificação na DFC de todas as empresas da amostra, isso porque, em alguns casos, as empresas não contabilizaram determinado evento, como o pagamento de dividendos e juros sobre o capital próprio, por exemplo, o que pode ser verificado pela análise da Demonstração das Mutações do Patrimônio Líquido (DMPL) em alguns anos.

É possível observar, também, que a maioria das empresas do Novo Mercado da B3, no período de 2010 a 2015, escolheu classificar juros pagos e recebidos no fluxo de caixa operacional, assim como os dividendos e juros sobre o capital próprio recebidos, e ainda, escolheu classificar os dividendos e juros sobre o capital próprio pagos no fluxo de caixa de financiamento. Tais classificações, escolhidas pela maior parte das empresas pesquisadas, vão ao encontro da recomendação constante no item 34A do CPC 03.

Com relação aos juros recebidos, importante destacar que os mesmos, em grande parte, decorrem do ajuste a valor presente de vendas a prazo (receitas financeiras de juros), operações realizadas predominantemente na amostra. Dessa forma, mesmo não sendo destacados em linha específica na DFC, podem ser identificados no fluxo de caixa operacional, uma vez que, pelo método indireto, se o lucro líquido não foi ajustado por tais juros, estes integram o fluxo de caixa operacional. Esse fato parece não ter sido observado por Maciel, Salotti e Imoniana (2017, p. 205), que mencionam que "essa é uma informação pouco divulgada, seja por falha dos preparadores da DFC ou pelo fato da informação não ser relevante, ou por algum outro motivo interno". Lembrando que tal procedimento de ajuste pode ser aplicado para os demais itens que tiveram sua classificação analisada. No contexto de quase totalidade de empresas utilizando o método indireto, isso implica que, para um estudo adequado da DFC, a análise conjunta das demais demonstrações contábeis (Demonstração de Resultado, DMPL e Balanço Patrimonial, pelo menos) é essencial, visto que foram raras as notas explicativas especificamente relacionadas à DFC na amostra investigada.

Adicionalmente, verificam-se algumas classificações que não constam como opções nas normas contábeis (CPC e/ou IFRS). Tratam-se das classificações de juros, dividendos e juros sobre o capital próprio recebidos no fluxo de caixa de financiamento, e de dividendos pagos, no fluxo de caixa de investimento. Situação parecida foi encontrada nas pesquisas da KPMG e Von Keitz (2006) e de Scherer et al. (2012), as quais evidenciaram que algumas empresas utilizaram essas classificações. Corroborando os últimos autores citados, entende-se que tais escolhas possam estar relacionadas à vinculação das receitas e despesas financeiras em um mesmo fluxo de caixa, mantendo consistência com o resultado financeiro líquido da DRE, ou pode, inclusive, ter sido um erro. Importante destacar que não foram encontradas notas explicativas a respeito das classificações dos fluxos de caixa diferentes do que recomenda o CPC, conforme requerido no item 34A do CPC 03, nem a respeito das classificações que destoam do previsto nas normas contábeis, possivelmente porque as empresas não julgaram relevante tal informação ou omitiram.

Na Tabela 3, verifica-se, também, que os itens com mais variabilidade de escolha entre as empresas da amostra e que possibilitam as análises propostas neste estudo referem-se aos juros pagos e aos dividendos recebidos. Com relação às escolhas de classificação dos juros recebidos e dos dividendos pagos, não houve um equilíbrio entre as opções, mas sim, a escolha maciça nas empresas, pela classificação no fluxo de caixa operacional e no fluxo de caixa de financiamento, respectivamente. Essa conjuntura inviabilizou as análises estatísticas propostas para tais eventos, que apresentaram uma elevada frequência de escolhas centradas em uma única categoria (fluxo de caixa operacional e fluxo de caixa de financiamento), no período estudado. Essas escolhas contábeis podem ser explicadas pela própria recomendação normativa ou podem ser um mimetismo do segmento analisado (Novo Mercado).

Desse modo, foram investigadas as características das empresas que podem incentivar a classificação dos juros pagos como fluxo de caixa das atividades de financiamento e não 
como fluxo de caixa das atividades operacionais, como recomenda o CPC 03, e a classificação dos dividendos recebidos como fluxo de caixa das atividades operacionais (política preferencial recomendada no CPC 03) e não de investimento, de modo a inflar o fluxo de caixa operacional. Para efeito das análises estatísticas, as escolhas contábeis que divergem das normas contábeis em vigor foram tratadas, neste estudo, como "não aplicáveis", ou seja, as células correspondentes a escolhas contábeis divergentes foram deixadas vazias.

Na Tabela 4 é apresentado o resultado do teste de diferença de médias das variáveis para o grupo de empresas que classificou juros pagos no fluxo de caixa operacional e o grupo de empresas que classificou juros pagos no fluxo de caixa de financiamento, assim como, para o grupo de empresas que classificou dividendos recebidos no fluxo de caixa operacional e o grupo de empresas que classificou dividendos recebidos no fluxo de caixa de investimento.

Tabela 4 - Diferenças de médias para duas amostras independentes

\begin{tabular}{lrrrrr}
\hline Juros pagos & END & ROE & TAM & FCO & PB \\
\hline Mann-Whitney U & 44004,000 & 40427,500 & 40570,500 & 42753,000 & 42528,500 \\
Wilcoxon W & 155632,000 & 58193,500 & 58525,500 & 154381,000 & 60483,500 \\
Z &,- 270 & $-1,782$ & $-1,818$ & $-1,195$ &,- 936 \\
Sig. Assint. (2 caudas) &, 787 &, 075 &, 069 &, 232 &, 349 \\
\hline Dividendos recebidos & END & ROE & TAM & FCO & PB \\
\hline Mann-Whitney U & 36551,000 & 37225,000 & 38195,500 & 38137,000 & 33946,000 \\
Wilcoxon W & 155867,000 & 49786,000 & 50756,500 & 157453,000 & 46507,000 \\
Z &,- 981 &,- 613 &,- 175 &,- 291 & $-2,259$ \\
Sig. Assint. (2 caudas) &, 326 &, 540 &, 861 &, 771 &, $024^{*}$ \\
\hline
\end{tabular}

Notas: TAM = tamanho; END = endividamento; ROE = rentabilidade; FCO: Fluxo de Caixa Operacional; PB = price-to-book. * diferença significativa ao nível de $5 \%$.

$\mathrm{Na}$ Tabela 4, os resultados do teste de Mann-Whitney apontam para a igualdade de médias dos dois grupos de empresas analisados referentes à escolha de classificação dos juros pagos, que demonstra, para todas as variáveis, que não há condições de rejeição da hipótese nula $\left(H_{0}\right)$ ao nível de significância de $5 \%$. Em outras palavras, o endividamento, a rentabilidade, o tamanho, o valor do fluxo de caixa operacional (se positivo ou negativo) e as oportunidades de crescimento são semelhantes, tanto para o grupo de empresas que escolheu classificar juros pagos no fluxo de caixa operacional, quanto para o grupo de empresas que escolheu classificar juros pagos no fluxo de caixa de financiamento.

Esses resultados sugerem que as empresas não financeiras listadas no Novo Mercado da B3 realizaram escolhas contábeis semelhantes em relação à classificação dos juros pagos na DFC, no período de 2010 a 2015, independentemente do endividamento, da rentabilidade, do tamanho, do fluxo de caixa operacional positivo ou negativo e das oportunidades de crescimento, ou seja, não se pode afirmar que essas variáveis possuem relação com as escolhas contábeis de classificação dos juros pagos na DFC.

No que diz respeito à escolha de classificação dos dividendos recebidos, observa-se, na Tabela 4, que os resultados do teste de Mann-Whitney apontam para a igualdade de médias dos dois grupos de empresas analisados (não rejeição da hipótese nula), com exceção da variável oportunidades de crescimento (price-to-book). De outro modo, o endividamento, a rentabilidade, o tamanho e o valor do fluxo de caixa operacional (se positivo ou negativo) são semelhantes, tanto para o grupo de empresas que escolheu classificar dividendos recebidos no fluxo de caixa operacional quanto para o grupo de empresas que escolheu classificar dividendos recebidos no fluxo de caixa de investimento.

Em relação às oportunidades de crescimento, deve-se rejeitar a hipótese nula $\left(H_{0}\right)$, isto 
é, empresas que escolheram classificar dividendos recebidos no fluxo de caixa operacional apresentam oportunidades de crescimento estatisticamente diferentes das empresas que escolheram classificar dividendos recebidos no fluxo de caixa de investimento. Pelos dados da pesquisa, o grupo que classificou dividendos recebidos no fluxo de caixa de investimento apresentou, em média, um price-to-book de 1,5 no período. O grupo que classificou dividendos recebidos no fluxo de caixa operacional apresentou, em média, um price-to-book de 2,5. Isso denota que empresas com mais oportunidades de crescimento escolhem classificações que aumentam o fluxo de caixa operacional, apoiando o que prega a literatura.

Portanto, por esse teste, não se pode afirmar que as variáveis endividamento, rentabilidade, tamanho e fluxo de caixa operacional positivo ou negativo possuem relação com as escolhas contábeis de classificação dos dividendos recebidos na DFC, realizadas nas empresas não financeiras listadas no Novo Mercado da B3 no período de 2010 a 2015. Por outro lado, referente à variável price-to-book, o teste implica que as oportunidades de crescimento podem estar relacionadas às escolhas de classificação dos dividendos recebidos na DFC, efetuadas nas referidas empresas no período especificado, ao nível de significância de $5 \%$.

Esses resultados se assemelham, em partes, ao estudo de Baik et al. (2016), em relação às oportunidades de crescimento, na medida em que os referidos pesquisadores defendem que as oportunidades de crescimento podem incentivar as empresas a realizarem escolhas contábeis que aumentem o fluxo de caixa operacional.

Para complementar as análises e compreender melhor a relação entre as características das empresas e as escolhas contábeis de classificação de juros pagos e dividendos recebidos na DFC, apresenta-se, na Tabela 5, a aplicação da regressão logística aos dados da pesquisa.

$\underline{\text { Tabela } 5 \text { - Resultados da análise de regressão logística }}$

\begin{tabular}{|c|c|c|c|c|c|c|c|c|}
\hline \multirow[b]{2}{*}{ Variáveis } & \multicolumn{4}{|c|}{ Juros pagos } & \multicolumn{4}{|c|}{ Dividendos recebidos } \\
\hline & Beta & $\begin{array}{r}\text { Erro } \\
\text { Padrão }\end{array}$ & Wald & Sig & Beta & $\begin{array}{r}\text { Erro } \\
\text { Padrão }\end{array}$ & Wald & Sig \\
\hline END &,- 008 &, 005 & 3,006 &, 083 &,- 003 &, 005 & ,322 &, 570 \\
\hline ROE &, 000 & ,001 &, 041 & ,839 &,- 001 & ,002 &, 140 & ,708 \\
\hline TAM & ,191 & 077 & 6,171 &, $013 *$ &, 058 &, 080 &, 523 & ,469 \\
\hline $\mathrm{FCO}$ &,- 405 & ,231 & 3,079 & ,079 &,- 192 & ,237 &, 656 & ,418 \\
\hline PB &,- 022 & ,026 & ,710 & ,399 & ,131 &, 046 & 8,326 &, $004 *$ \\
\hline Constante & $-1,402$ & 1,113 & 1,588 & ,208 & ,261 & 1,166 &, 050 & ,823 \\
\hline $\mathrm{N}$ & 672 & ---- & ---- & ---- & 649 & ---- & ---- & ---- \\
\hline $\mathrm{R}^{2}$ Cox \& Snell & 015 & ---- & ---- & --- & ,020 & ---- & ---- & ---- \\
\hline $\mathrm{R}^{2}$ Nagelkerke &, 021 & ---- & ---- & ---- &, 030 & ---- & ---- & ---- \\
\hline $\begin{array}{l}\text { Qui-quadrado } \\
\text { (sig) }\end{array}$ &, $000 *$ & ---- & ---- & ---- & ,765 & ---- & ---- & ---- \\
\hline
\end{tabular}

Notas: variável dependente do modelo $=$ CLAS, sendo $1=$ classificação no fluxo de caixa operacional; $0=$ classificação no fluxo de caixa de financiamento (juros pagos) e classificação no fluxo de caixa de investimento (dividendos recebidos); TAM = tamanho; $\mathrm{END}=$ endividamento; $\mathrm{ROE}=$ rentabilidade; $\mathrm{FCO}: 1$ = fluxo de caixa operacional positivo; 0 = fluxo de caixa operacional negativo; $\mathrm{PB}=$ price-to-book; $\mathrm{N}$ = número de observações; Qui-quadrado (sig) = significância para o teste de Hosmer e Lemeshow. * significante ao nível de 5\%.

Conforme descrito na Tabela 5, as medidas de Cox \& Snell e Nagelkerke, que são medidas semelhantes ao $\mathrm{R}^{2}$ da regressão, apresentam um poder explicativo de apenas $1,5 \% \mathrm{e}$ $2,1 \%$, respectivamente, para a escolha de classificação de juros pagos, e de $2,0 \%$ e 3,0\%, para a escolha de classificação dos dividendos recebidos. Embora o modelo tenha baixo poder explicativo, dado pelas estatísticas de Cox \& Snell e Nagelkerke, o teste de Hosmer e Lemeshow (estatística Qui-quadrado), cuja aplicação consiste na comparação entre os eventos 
observados e esperados, sugere que há diferenças significativas entre as frequências previstas e observadas ao nível de significância de 5\%, para os juros pagos, tendo em vista o sig inferior a 0,05 . Isso implica que pelo menos uma variável (no caso, o tamanho) é estatisticamente significante para explicar a probabilidade de classificação dos juros pagos no fluxo de caixa operacional ou no fluxo de caixa de investimento.

Em relação à escolha de classificação dos juros pagos, os parâmetros estimados se mostraram significativos ao nível de 5\% para a variável tamanho, uma vez que os valores do sig são inferiores a 0,05 . Dessa forma, há que se atentar para a correta interpretação do coeficiente dessa variável. De acordo com Fávero et al. (2009, p. 453), "quando o coeficiente for maior que zero, maior será a probabilidade de ocorrência do evento de interesse e viceversa". Nesse sentido e, considerando que o evento de interesse é a classificação de juros pagos no fluxo de caixa operacional (CLAS $=1$ ), pelo exposto na Tabela 5 , cada $1 \%$ de variação no tamanho, aumenta em 19,1\% a probabilidade de classificação dos juros pagos no fluxo de caixa operacional. Isso quer dizer que, na amostra estudada, as empresas maiores não tendem a fazer escolhas contábeis que aumentam o fluxo de caixa operacional, pois há maior probabilidade de elas escolherem classificar juros pagos neste fluxo, ao invés de classificar no fluxo de caixa de financiamento. Essa conclusão contraria os achados de Baik et al. (2016) em relação a empresas da Coreia do Sul.

Os resultados da Tabela 5 revelam, também, que, ao nível de significância de 5\%, não há indícios de que empresas não financeiras listadas no Novo Mercado da B3 mais endividadas, com fluxo de caixa operacional negativo e/ou com mais oportunidades de crescimento realizam escolhas contábeis de classificação dos juros pagos na DFC com intuito de aumentar o fluxo de caixa operacional, diferentemente do que encontraram Gordon et al. (2013) e Baik et al. (2016). No que se refere à rentabilidade, o resultado é semelhante ao encontrado por Gordon et al. (2013).

Relativamente aos dividendos recebidos, observa-se, na Tabela 5, que os parâmetros da variável price-to-book, representativa das oportunidades de crescimento, foram significativos ao nível de $5 \%$. Pela análise dos coeficientes, verifica-se que cada $1 \%$ de variação nas oportunidades de crescimento aumenta em $13,1 \%$ a probabilidade de classificação de dividendos recebidos no fluxo de caixa operacional, similarmente aos achados de Baik et al. (2016). Em outras palavras, as oportunidades de crescimento parecem ser incentivos para escolhas de classificação que aumentem o fluxo de caixa operacional nas empresas não financeiras listadas no Novo Mercado da B3.

Por sua vez, as variáveis endividamento, rentabilidade, tamanho e valor (positivo ou negativo) do fluxo de caixa operacional não foram significativas, denotando que elas não representam incentivos para as empresas não financeiras listadas na B3 escolherem classificar dividendos recebidos no fluxo de caixa operacional, aumentando, dessa forma, esse fluxo, apoiando, no que tange à rentabilidade, as conclusões de Gordon et al. (2013). Ademais, esses resultados corroboram, parcialmente, o que demonstrou o teste de Mann-Whitney, visto que, por meio desse teste, ao nível de significância de 5\%, apenas a variável oportunidades de crescimento parece ter relação com as escolhas de classificação de dividendos recebidos.

Comparativamente à pesquisa realizada por Pinto et al. (2018), os resultados do presente estudo também são diferentes. Os autores mencionados tiveram como objetivo determinar os níveis de comparabilidade entre as escolhas contábeis na DFC das empresas brasileiras de capital aberto e descobrir os fatores que poderiam explicar essas escolhas. Eles encontraram relação entre: (i) o endividamento e a classificação de juros pagos e de impostos sobre o lucro; (ii) a rentabilidade e a classificação de dividendos pagos; (iii) o fluxo de caixa operacional negativo e a classificação dos juros recebidos e dos impostos sobre o lucro; (iv) o tamanho e a classificação de juros recebidos e de dividendos recebidos e pagos; e (v) as oportunidades de crescimento e a classificação de juros recebidos. Pinto et al (2018) concluíram, portanto, que 
há evidências de relações parciais entre todas as variáveis que pesquisaram e as escolhas contábeis na DFC. Um resumo dos resultados comparativamente aos estudos anteriores em discussão é apresentado no Quadro 2.

Quadro 2 - Comparação dos resultados com estudos anteriores
\begin{tabular}{|l|l|l|l|l|}
\hline Variável & Escolhas de classificação na DFC & \multicolumn{2}{c|}{ Escolhas que aumentam o FCO } \\
\cline { 2 - 5 } & Este estudo & Pinto et al. (2018) & $\begin{array}{l}\text { Gordon et al. } \\
(2013)\end{array}$ & Baik et al. (2016) \\
\hline Endividamento & Não há relação & Relação parcial & Há relação & Há relação \\
\hline Rentabilidade & Não há relação & Relação parcial & Não há relação & Há relação \\
\hline FCO negativo & Não há relação & Relação parcial & Há relação & Não avaliou \\
\hline Tamanho & $\begin{array}{l}\text { Relação } \\
\text { parcial }\end{array}$ & Relação parcial & Não avaliou & Há relação \\
\hline $\begin{array}{l}\text { Oportunidades de } \\
\text { crescimento }\end{array}$ & $\begin{array}{l}\text { Relação } \\
\text { parcial }\end{array}$ & Relação parcial & Não avaliou & Há relação \\
\hline
\end{tabular}

Nota: FCO = Fluxo de Caixa Operacional.

Destarte esses resultados, denota-se que as variáveis relatadas podem explicar parcialmente as escolhas contábeis de classificação na DFC e, ainda, que outras variáveis aqui não avaliadas podem complementar as explicações das mencionadas escolhas contábeis, tais como, o ambiente de divulgação (país de origem e de listagem), setor, auditoria, projeções de analistas etc., conforme alertaram Cole, Branson e Breesch (2013) e Gordon et al. (2013). Considera-se que essas características podem explicar, por exemplo, porque algumas variáveis estudadas se mostraram significativas no contexto brasileiro e não em países europeus e/ou da Coreia do Sul, conforme os estudos de Gordon et al. (2013) e Baik et al. (2016), e vice-versa. Não se pode deixar de mencionar, também, a possível influência normativa, advinda da recomendação de determinadas políticas contábeis preferenciais por parte do CPC.

\section{Considerações Finais}

A partir do objetivo delineado para este estudo, pode-se concluir que as escolhas contábeis predominantes na DFC das empresas não financeiras listadas no Novo Mercado da B3, no período de 2010 a 2015 são: método indireto para apresentação da DFC; classificação de juros pagos e recebidos no fluxo de caixa operacional; classificação de dividendos e juros sobre capital próprio pagos no fluxo de caixa de financiamento; e classificação de dividendos e juros sobre capital próprio recebidos no fluxo de caixa operacional. Essas escolhas vão ao encontro das políticas contábeis recomendadas, tanto no CPC 03 quanto na IAS 7. Dessa forma, verifica-se que as empresas listadas no Novo Mercado da B3, considerado um segmento de listagem de alto nível de governança corporativa, apresentam compliance com as políticas contábeis recomendadas nas normas, assim como discutido por Verriest, Gaeremynck e Thornton (2013). Pelas razões apresentadas anteriormente (seção 3.2), conclui-se que isso não reflete, essencialmente, divulgação de maior qualidade.

Em se tratando da apresentação da DFC, a escolha quase unânime das empresas pelo método indireto não corresponde às preferências dos órgãos normatizadores (IASB/FASB), que incentivam o emprego do método direto. No Brasil, o CPC não traz uma recomendação específica quanto ao método de apresentação da DFC, mas determina que as empresas que apresentarem pelo método direto devem, obrigatoriamente, demonstrar a conciliação do lucro líquido com o fluxo de caixa líquido em notas explicativas. Possíveis explicações para essa escolha relacionam-se à percepção dos elaboradores das demonstrações contábeis de que o método indireto é de mais fácil entendimento por parte dos usuários e de menor custo de elaboração, além de oferecer a conciliação do lucro líquido na própria demonstração. O método indireto também foi predominantemente aplicado por empresas de diversos países, como 
apontaram os estudos da KPMG e Von Keitz (2006), Nobes (2011), Scherer et al. (2012) e Cole, Branson e Breesch (2013), revelando que as empresas analisadas podem, ainda, estar seguindo uma tendência mundial.

Em contrapartida, os principais normatizadores contábeis do mundo (IASB e FASB) expressaram por meio do Staff Draft of an Exposure Draft on Financial Statement Presentation, publicado em 2010, que o método direto melhora a utilidade da informação contábil para os diversos usuários, devido a algumas vantagens, elencadas no item $\mathrm{BC} 172$ do draft, tais como: o método direto é mais intuitivo e compreensível; aprimora a capacidade de prever fluxos de caixa futuros; melhora a visão sobre o ciclo de conversão de caixa de uma entidade e sobre a relação entre receitas e despesas apresentadas na demonstração de resultado e fluxo de caixa; resulta em informação que é superior a quaisquer derivações nas quais até mesmo o analista mais qualificado chegaria, entre outras (FINANCIAL ACCOUNTING STANDARDS BOARD, 2010).

Com relação às escolhas contábeis de classificação, foram focadas as classificações dos juros pagos e dos dividendos recebidos. Tomando por base, única e exclusivamente, esses dois eventos, chega-se a algumas conclusões sobre as hipóteses levantadas no estudo.

A hipótese $\mathrm{H} 1$, que afirma que o nível de endividamento possui relação com as escolhas contábeis na DFC foi rejeitada, pois, não há indícios de que o nível de endividamento impacta as escolhas contábeis de classificação dos juros pagos e dos dividendos recebidos na DFC das empresas não financeiras listadas no Novo Mercado da B3, no período de 2010 a 2011 . Em linha com os estudos anteriores apresentados, no contexto dessa pesquisa, empresas mais endividadas não tendem a fazer escolhas de classificação na DFC que aumentem o fluxo de caixa operacional, como, classificar juros pagos no fluxo de caixa de financiamento e dividendos recebidos no fluxo de caixa operacional.

A segunda hipótese levantada (H2) menciona que o índice de rentabilidade possui relação com as escolhas contábeis na DFC e também foi rejeitada, uma vez que a rentabilidade não parece impactar as escolhas contábeis de classificação dos juros pagos e nem as escolhas contábeis de classificação dos dividendos recebidos nas empresas não financeiras listadas no Novo Mercado da B3, no período de 2010 a 2015. Em linhas gerais, a rentabilidade também não parece ser um incentivo para a realização de escolhas contábeis que aumentem o fluxo de caixa operacional.

A hipótese $\mathrm{H} 3$ refere-se à relação entre o valor (positivo ou negativo) do fluxo de caixa operacional e as escolhas contábeis na DFC. Essa hipótese foi rejeitada, tendo em vista que não há indicativos estatisticamente significantes, ao nível de $5 \%$, de que o valor (positivo ou negativo) do fluxo de caixa operacional está relacionado às escolhas contábeis na DFC realizadas nas empresas não financeiras listadas no Novo Mercado da B3 no período de 2010 a 2015.

A partir dos resultados obtidos, a hipótese $\mathrm{H} 4$, referente à relação entre o tamanho da empresa e as escolhas contábeis na DFC, foi rejeitada parcialmente, já que há indícios de que o tamanho da empresa impacta as escolhas contábeis de classificação dos juros pagos na DFC efetuadas nas empresas não financeiras listadas no Novo Mercado da B3, no período de 2010 a 2015. No entanto, depreende-se que as empresas maiores tendem a classificar os juros pagos no fluxo de caixa operacional, diminuindo, consequentemente, esse fluxo, o que contraria os achados de estudos anteriores.

Por fim a hipótese H5, que afirma que as oportunidades de crescimento possuem relação com as escolhas contábeis na DFC, também foi rejeitada parcialmente, considerando-se que as oportunidades de crescimento podem impactar as escolhas contábeis de classificação dos dividendos recebidos na DFC realizadas nas empresas não financeiras listadas no Novo Mercado da B3 no período de 2010 a 2015. De acordo com os resultados, as empresas com mais oportunidades de crescimento tendem a escolher classificações que aumentam o fluxo de 
caixa operacional, ou seja, tendem a classificar dividendos recebidos nesse fluxo.

Com isso, entre as variáveis testadas, apenas o tamanho e as oportunidades de crescimento parecem ter relação com as escolhas de classificação de juros pagos e dividendos recebidos na DFC, respectivamente, considerando a amostra e o período estudados. Em linhas gerais, os resultados não condizem com pesquisas anteriores em outros mercados, provavelmente por implicações de outras variáveis aqui não analisadas, tais como aquelas que traduzem algum aspecto do ambiente institucional (setor, país de origem, estrutura de propriedade, empresa de auditoria etc.).

Os resultados encontrados podem auxiliar na complementação da literatura sobre escolhas contábeis, pois evidencia que no Brasil, similarmente aos resultados obtidos por outros estudos em outros países (LEE, 2012; GORDON et al., 2013; BAIK et al., 2016), houve algumas evidências significativas da utilização de escolhas contábeis para gerenciar os fluxos de caixa.

Deve-se levar em consideração que o mercado de capitais brasileiro é bastante diferente dos mercados norte-americano, europeu e asiático, base dos estudos utilizados. Por isso, conclusões e comparações com os resultados encontrados devem ser feitas com cautela. Essa cautela se estende à generalização dos resultados em razão de fatores limitantes do estudo, conforme citado ao final da seção de aspectos metodológicos.

Aumentar o tamanho da amostra, considerando os demais níveis de governança corporativa da $\mathrm{B} 3$, e agregar outras variáveis ao modelo, como por exemplo, do âmbito institucional, são etapas futuras para continuar testando as variáveis e seus efeitos nas escolhas contábeis na DFC no Brasil e em outros países.

\section{Referências}

ABU-ABBAS , B. M. Direct, Indirect, or Both Methods of Reporting Operating Statement of Cash Flows. International Journal of Finance and Accounting, v. 3, n. 6, p. 335-340, 2014. doi:10.5923/j.ijfa.20140306.01

ANDRADE, M. E. M. C.; SILVA, D. M. Demonstração dos Fluxos de Caixa pelo método direto ou indireto? Revista Mineira de Contabilidade, v. 18, n. 1, p. 5-15, 2017.

BAIK, B.; CHO, H.; CHOI, W.; LEE, K. Who classifies interest payments as financing activities? An analysis of classification shifting in the statement of cash flows at the adoption of IFRS. Journal of Accounting and Public Policy, v. 35, n. 4, p. 331-351, 2016.

https://doi.org/10.1016/j.jaccpubpol.2015.11.003

BOND, D., BUGEJA, M.; CZERNKOWSKI, R. Did Australian Firms Choose to Switch to Reporting Operating Cash Flows Using the Indirect Method? Australian Accounting Review, v. 22, n. 1, p. 18-24, 2012 https://doi.org/10.1111/j.1835-2561.2011.00156.x

BRADBURY, M. Direct or Indirect Cash Flow Statements? Australian Accounting Review, v. 57, n. 21, p. 124-130, 2011.

CLACHER, I.; RICQUEBOURG, A. D.; HODGSON, A. The Value Relevance of Direct Cash Flows under International Financial Reporting Standards. Abacus, v. 49, n. 3, p. 367395, 2013. https://doi.org/10.1111/abac.12010

COLE, V.; BRANSON, J.; BREESCH, D. Determinants Influencing the IFRS Accounting Policy Choices of European Listed Companies. Working Paper, 2013. Available at SSRN: 
http://ssrn.com/abstract=2217498 or http://dx.doi.org/10.2139/ssrn.2217498 Accessed in: 01 dec. 2014.

COMITÊ DE PRONUNCIAMENTOS CONTÁBEIS. Pronunciamento Técnico CPC 03 Demonstração dos Fluxos de Caixa. Disponível em: $<$ http://www.cpc.org.br $>$. Acesso em: 21 jan. 2013.

FÁVERO, L. P.; BELFIORE, P.; SILVA, F. L.; CHAN, B. L. Análise de Dados: modelagem multivariada para tomada de decisões. Rio de Janeiro: Elsevier, 2009.

FIELDS, T. D.; LYS, T. Z.; VINCENT, L. Empirical research on accounting choice. Journal of Accounting and Economics, v. 31, p. 255-307, 2001. https://doi.org/10.1016/S01654101(01)00028-3

FINANCIAL ACCOUNTING STANDARDS BOARD. Staff Draft of an Exposure Draft on Financial Statement Presentation. Norwalk, CT, 2010. Available at:

$<$ http://www.fasb.org/jsp/FASB/Document_C/DocumentPage?cid=1176156966501\&accepte dDisclaimer=true $>$. Accessed in: 02 feb. 2015.

FINANCIAL ACCOUNTING STANDARDS BOARD. Statement of Financial Accounting Standards $N^{\circ} 95$ (FAS 95) - Statement of Cash Flows. Available at:

$<$ http://www.fasb.org/pdf/fas95.pdf >. Acessed in: 02 feb. 2015.

GORDON, E. A.; HENRY, E.; JORGENSEN, B. N.; LINTHICUM, C. L. Flexibility in Cash Flow Reporting Classification Choices under IFRS. Working Paper, 2013. Available at: $<$ http://ssrn.com/abstract=2439383 >. Accessed in: 06 feb. 2014.

GORDON, E. A.; HENRY, E.; JORGENSEN, B. N.; LINTHICUM, C. L. Flexibility in cashflow classification under IFRS: determinants and consequences. Review of Accounting Studies, v. 22, n. 2, p. 839-872, 2017. DOI 10.1007/s11142-017-9387-1

IFRS FOUDATION. International Accounting Standard $N^{\circ} 7$ - Statement of Cash Flows (IAS 7). Available at: $<$ http://eifrs.ifrs.org/eifrs/bnstandards/en/ias7.pdf $>$. Acessed in: 02 feb. 2015.

HALES, J.; ORPURT, S. F. A Review of Academic Research on the Reporting of Cash Flows from Operations. Accounting Horizons, v. 3, p. 539-578, 2013.

HOLTHAUSEN, R. W.; LEFTWICH, R. W. The Economic consequences of accounting choice: implications of costly contracting and monitoring. Journal of Accounting and Economics, v. 5, p. 77-117, 1983.

HOLTHAUSEN, R. W. Accounting method choice: opportunistic behavior, efficient contracting and information perspective. Journal of Accounting and Economics, v. 12, p. 207-281, 1990.

KMPG, VON KEITZ, I. The application of IFRS: choices in practice. London: KPMG, 2006.

LEE, L. F. Incentives to inflate reported Cash from Operations using classification and 
timing. The Accounting Review, v. 87, n. 1, p. 1-33, 2012.

MACIEL, F. F. S.; SALOTTI, B. M.; IMONIANA, J. O. Escolhas contábeis na Demonstração dos Fluxos de Caixa no contexto do mercado de capitais brasileiro. Revista Universo Contábil, v. 13, n. 4, p. 194-211, 2017.

NOBES, C. IFRS Practices and the Persistence of Accounting System Classification. Abacus, v. 47, n. 3, p. 267-283, 2011.

PINTO, A. F.; COSTA, P. S.; NUNES, F. M.; LEMES, S. Comparability of Accounting Choices in the Statement of Cash Flow: Evidence from Brazil. Contaduría y

Administración, 2018, próxima publicación.

SCHERER, L. M.; TEODORO, J. D.; KOS, S. R.; ANJOS, R. P. Demonstração dos Fluxos de Caixa: análise de diferenças de procedimentos de divulgação entre empresas listadas nas bolsas de valores de São Paulo, Frankfurt, Milão e Londres. Revista de Contabilidade e Controladoria, v. 4, n. 2, p. 37-51, 2012.

TORRES FILHO, E. T.; COSTA, F. N.; BNDES e o financiamento do desenvolvimento. Economia e Sociedade, v. 21, número especial, p. 975-2009, 2012.

VERRIEST, A.; GAEREMYNCK, A.; THORNTON, D. B. The Impact of Corporate Governance on IFRS Adoption Choices. European Accounting Review, v. 22, n. 1, p. 39-77, 2013. https://doi.org/10.1080/09638180.2011.644699

WATTS, R. L. Accounting Choice Theory and Market-Based Research in Accounting. British Accounting Review, v. 24, p. 235-267, 1992. https://doi.org/10.1016/S08908389(05)80023-X

* Uma versão preprint do artigo foi apresentado no XXXVIII Encontro da Anpad, 2014. 